\section{NOTES OF FOUR CASES}

\section{ACUTE ANTERIOR POLIOMYELITIS.*}

By W. WITHERS MOORE, M.D., F.R.C.P., President of the South-Eastern Branch of the British Medical Association.

CASE I.-On the 25th September, I879, Mr. Kempe (Shoreham) was sent for to a gentleman, whom he found suffering from pains in the back, with constant desire to pass urine, a very little passing at a time; the pains extended to the buttocks, over the hips, and down to the testicles, the right one especially. The urine, though clear, contained a copious deposit of red sand. Potash, opium, and rest in bed, were ordered, and were followed by marked relief of the pain; but the uric acid deposit continued for some time.

On the 26 th, he was up, but loss of power in the legs had begun to be manifest.

On the 29th, paralysis was now complete in both legs. There was no pain. The urine was still charged with uric acid, and had to be drawn off with a catheter.

October 3 oth. The catheter had been used for about three weeks, but was now no lorger needed. He had complete power over the sphincter ani. The urine was clear, and free from deposit. The interrupted current was now applied. There was no reflex action in the right leg, and very little in the left. Iodide of potassium and nux vomica were given internally.

On November I8th, I879, I saw the patient for the first time-a short, stout, healthy-looking man, about forty-eight years of age. $\mathrm{He}$ had enjoyed good health until about two years ago, when he was treated for "weak circulation". During the last twelve months, he had suffered from pain in the back, and aching pains down the back of his thighs, which he attributed to standing about on wet ground. He had been a total abstainer for the last three years or more. There was a history of slight specific affection twenty years ago, which had not been followed by any secondary affection, save a slight thickening of the tongue.

Present State. - His general health was good. The bodily functions were regular. There was no paralysis of the bladder or of the sphincter ani; but he was unable to turn in bed without his legs and body being moved for him. Sensation was perfect in both legs, but reflex excitability was entirely gone. The right leg was wholly powerless; there was the slightest pussible movement in the left one, but he could not raise it or shift its position. The interrupted current, although keenly felt, produced no contraction of the muscles, but they were not wasted, nor had he any pain now in the legs. There was no tenderness on percussion down the spine, nor did the hot sponge produce any special
localised effect.

On March 8th, 1880, Mr. Kempe kindly furnished me with the subjoined report of the patient's state at that time. There was not much improvement up to the end of the year 1879 , although he became able to move himself in bed. He would not use the constant current (which I had suggested to be used in addition to pushing the dose of iodide of potassium) any longer, but would try the interrupted current again, since which time he had improved much. He could now, when sitting up, drag his left leg up quickly when stretched out, and could extend it by working it on his toes, but could not lift it off the ground. The muscles contracted on the application of electricity, plainly in the left lower limb, but not much in the right, except the thigh. He could not move the right leg as a whole, but could move the muscles on the inside of the thigh at will. The muscles of the left leg were very slightly wasted. The right leg pitted on pressure. Sensation was acute. He had very great sexual desire, and nocturnal emissions about once a week. Since he had been under treatment for this illness, his tongue had become right-the first time for twenty years. He could raise himself in his chair sufficiently to alter his position when he wished, and could turn in his bed without assistance, with the help of a rope hung from the top of the bed. He did not smoke tobacco. The left arm, which had been weak, was now quite strong again. He was still taking the

On August 2oth, Mr. Kemp wrote me: "The patient is much better. when he is in bed, he can draw up his left leg a little way, and put it down again, but cannot move the right leg much. He gets on crutches,

$$
\text { * Read at a meeting of the Brighton Medico-Chirurgical Society. }
$$

and moves about by making a circular sweep with his left leg to bring it forward, and hitching his right leg forward by a jerk from the hip. Health very good."

CASE II. - On March IIth, I880, I saw, in consultation with Mr. Salzmann, G. N., aged six months, the daughter of respectable parents. The family history showed a remarkable tendency to neuropathic dis. orders. The grandparents on the male side were cousins. Three or four of her uncles and aunts squinted, and several of her cousins. An uncle had infantile paralysis at one and a half years of age; and although he had recovered sufficiently well to walk without any assistance, the affected leg was still greatly wasted, and shorter than its fellow. A cousin died at two years, paralysed on one side; and another, a short time since, from cerebral disease.

The mother of G. N., while pregnant with her, had a severe mental shock, but the labour was rapid, and occurred at the full time. The infant was apparently well-nourished and healthy, save that the breathing from the first was markedly diaphragmatic; she had no special ailment until within two days of her death. She, however, never cried out, as other infants do, but gave a feeble wail ; the power of sucking, too, was impaired. She never once was sick. Micturition and defrecation occurred at ordinary intervals. Sensation was perfect, so far as could be ascertained. She never "kicked about", but she moved her limbs a little occasionally, stretching them out. When I saw her, she was lying quietly in her mother's lap; the countenance was placid, and free from all appearance of discomfort. The body was well nourished; the limbs rounded, but flaccid, devoid of all tonicity, and if moved they followed the law of gravity. All the voluntary muscles of the body seemed paralysed, save those of the head and jaw. Respiration was carried on entirely by the diaphragm, which, on descending, drew the chest-walls downwards and inwards from lack of the countervailing force of the intercostals, the abdominal muscles paralysed. Expiration must have been effected by the elastic recoil of the lungs and diaphragm. Little could be attempted in the way of cure. The continuous current and a ferruginous tonic were ordered; and I ventured to predict that, if the little one caught a cold, death would soon supervene, as it could not cough, and already its feeble breathing was only just sufficient for Nature's wants. Three days after I saw the child, it caught its first and last cold. The dyspnca was great, and much aggravated by inability to cough; and in two days death ended these symptums.

CASE III.-F. W., aged 29, a Swiss cook, was readmitted into the hospital on July 7 th, I 880 , having left it after a few days' stay on June 9 th. He remained for two weeks at business, but had all the time what he described as rheumatic pains, both in legs and arms. A week before his readmission, being unable to walk, he took to his bed, and remained there until he came to the hospital. This last change was sudden, and especially marked by pains in his back and limbs; there was also slight epistaxis for several nights, and some occasional sickness; but he had not lost much flesh. He owned to having drank a good deal, but did not give a reliable account of his previous state of health.

On admission, he was spare; his countenance was pale and anxious ; his limbs tremulous; and he lay in bed in a weak, helpless condition. The skin was warm and moist. Evening temperature, 100. $6^{\circ}$. The tongue was clean and moist; the bowels regular, and the sphincter ani competent. There was occasional involuntary micturition. The urine was of specific gravity 1020 , alkaline, no albumen nor sugar. The voice was whispering. Deglutition was somewhat impaired. He was unable to walk, and scarcely able to turn in bed; he could, however, lift each leg from the bed; not so his arms, which he only wriggled along the bed, and if either were raised for him, it trembled and fell down. There was no marked wasting. Reflex excitability was exaggerated, tickling the soles of the feet causing movements, not only in both legs, but also in both arms and the body generally. The muscles reacted slightly to faradisation. Sensibility seemed everywhere perfect. Respirations 28. The lungs were healthy. The heart's action was hurried. Pulse 124. The area of cardiac dulness was not increased. A softblowing systolic bruit was heard all over the cardiac region, loudest at the base and to the left. The abdomen was swollen. Hepatic dulness was somewhat decreased. There was no pain nor tenderness in the hepatic region; no enlargement of the spleen. On both tibix there were numerous faded patches of purpura. I ordered bark and hydrochloric acid.

On the I2th, his voice was still whispering, and there was still some dysphagia. The tongue was clean and tremulous. The pupils were equal ; no nystagmus. He slept well. Pulse I 20 . Temperature 99.6. He had a little more power in his arms, but could make very feeble resistance with them; being left-handed, the left was the stronger of the two. He could not feed himself, but took spoor -food fairly. The 
urine was still alkaline and ammoniacal, but was passed voluntarily. I ordered five grains of iodide of potassium in an ounce of decoction of cinchona three times a day.

July 28th. He was manifestly wasting, more especially the muscles of the chest (pectorales), shoulders, and upper arms. He had passed a restless night, and was not nearly so well. The temperature last night was 104. $6^{\circ}$. Although free from pain, he had vomited everything he had taken. The tongue was moist and red. He had some thirst. The bowels acted freely. The urine was of specific gravity rorg, slightly alkaline; no albumen. Respiration 26. Pulse I40, soft, compressible. The pupils were equal, and acted fairly. He moved the left arm better than the right, but had a difficulty in opening his fingers. I ordered fifteen minims of extract of ergot every four hours.

July 3Ist. His condition was somewhat improved. Evening temperature $99.8^{\circ}$, and pulse 142 . This morning, pulse 130, feeble. The first sound of the heart was now only muffled at the base. $\mathrm{He}$ could walk with assistance, and sit up for a short time each day. The muscular wasting of the chest and arms increased. No fibrillar contractions were shown on percussion.

August 18th. He was much improved as to general health; was out of bed, and able to walk with but slight assistance. The arms were much the same. The continuous current was ordered to be applied daily to the spine and wasted muscles. He was ordered liquor arsenicalis and liquor strychniæe, five minims of each three times a day.

August 26th. He had held his ground well; and walked without assistance. His gait was a little tottering from debility. The muscles of the legs had increased in bulk. The voice was husky, but no longer whispering. His spirits were good. The bodily functions were regular.

October. The man has improved in health, and can walk fairly well. By swinging the arm, i.e., by bringing into play the serratus magnus, he can raise the limb to his head. The trapezius and deltoid muscles react well ; the extensor muscles of the forearm slightly; the biceps, pectoralis, and flexors of the forearm not at all.

CASE IV.-A. P. M., aged 15, the offspring of cousins, had fair health until he had scarlet fever some years ago. He had always had heaithy habits, and his moral tone was high. He was fairly nourished, and latterly had been growing rapidly. Two or three weeks ago, he returned from a tour with his father in Scotland, where he had walked long distances and done some climbing. Being considered a little overdone, he had come to Brighton for his health. On the morning of Monday, the 9th September, 1878 , he awoke with a slight headache, and thought he had slept too warmly clothed; he believed a bath would do him good, and had a swim in the sea. He felt ill immediately afterwards, but recovered sufficiently to eat some dinner. He lay on the sofa with headache, and complained of being chilly all the afternoon. Towards night, he became very feverish, and complained of pain low down in his side. He had a good night; and on Tuesday morning seemed almost as well as usual, eating and drinking well and walking out.

On the afternoon of the 12 th, he had a drive for about an hour and a quarter, the weather being fresh and the wind north; but he was warmly clad, and said he did not feel the cold. Immediately on his return home, soon after 6 P.M., he complained of being very cold and chilly; nevertheless, he ate a good tea, and soon afterwards headache came on, followed by increase of temperature and restlessness. At 9 P.M., he fell asleep, but awoke before I A.M. complaining of intense pain in the loins and all round the lower part of the body. The pain increased, and was at times almost intolerable, causing him to writhe about, and it continued during Friday, the $13^{\text {th. }} \mathrm{He}$ was made to inhale a few drops of nitrite of amyl, which produced a short hysterical spasm; after which time the pain in the back was never so severe, but he complained very much more of his head. The pain in the head and back continued to alternate, the one being always worse when the other was better.

On Saturday, September I4th, I saw him for the first time. He had passed a restless night, owing to severe racking pains in the loins. His countenance was anxious, expressive of intense pain, which was principally localised in the lumbar region, where there was great tenderness on pressure, most marked over the left kidney. Skin dry. Temperature IOI. $2^{\circ}$; pulse 120 , of fair power and regular. The tongue had a white fur, with red tip and edges. He had some thirst, no vomiting, but unwillingness to take food. The bowels were constipated. 'The urine was clear, high-coloured, and contained an abundance of uric acid granules, no albumen. He was ordered hot poultices to the loins; a large enema with an ounce of castor-oil in it; some pills containing $1 / 2$ grains of camphor and $21 / 2$ grains of extract of henbane every two hours, together with a draught containing half a drachm of citrate of potash and two minims of tincture of aconite in cinnamon water.
Barley-water, milk, lime or potash water, and plain water, were ordered, but beef-tea was prohibited. In the evening, the skin was moist; temperature the same; pulse I08. The enema had comforted him, but had brought away very little fæeculent matter. An abundance of urine had been passed, with scarcely a trace of uric acid. The pains in the loins were greatly relieved; and he had had some sleep. There was some slight difficulty in swallowing, most marked when he first began to swallow. His head, too, was thrown back, and he required assistance to move it. This condition had been present some hours; but no complaint had been made of it. Sensation and motion in the limbs were unimpaired. The medicine was ordered to be given only every four hours.

September I5th, 8.15 A.M. He had passed a quiet night, sleeping well at intervals. Skin moist. Temperature I01.2 $2^{\circ}$. Pulse 108. Respiration normal. He had no pains in the loins; no tenderness on percussion of the spine until the part about the fourth and fifth curved vertebra was reached, where also a hot sponge gave a special burning sensation. The lower limbs were becoming powerless, more especially the right one ; sensation was perfect, and reflex irritability somewhat exaggerated. Both hands had had transient sensations of pins and needles, and were somewhat feeble. The head was now thrown forward, but assistance was still needed to move it; he had also to be turned in bed. There was still some slight dysphagia. The pupils were equal, but contracted. No delirium; mental faculties unimpaired; voice feeble. The tongue was furred, with red tip and edges. He had taken liquid nourishment fairly. The bowels were still confined. Urine was abundant, and free from all deposits. Pulse I Io, compressible. The heart-sounds were free, but the first sound was indistinct at the base. He was ordered half an ounce of castor-oil, to be followed in three hours by an enema, and twenty minims of liquid extract of ergot every two hours, two drachms of brandy every two hours, and milk and beef-tea alternately every two hours. An ice-bag was ordered to be applied to the nape of the neck; and he was directed to lie on the side, or better on the face, with the feet, if possible, below the level of the body.-Evening. He had passed a quiet day. The lumbar pains were gone, but there was some uneasiness in the cervical region, and inability to move the head or lower limbs, but he could work the toes of the left foot. At II P.M., Dr. Althaus of London saw him with me. He lay on the left side; there was no rigidity of any limb; sensation was acute; reflex excitability was gone, but irritation of the soles of the feet gave much discomfort, there being no reflex discharge (an interrupted yawn). The pupils were still contracted, and somewhat intolerant of light. There was no headache, but he had rambled a little on first awaking. His voice was feeble; clenching the jaw gave a little discomfort in the temporal region and the articulation of the jaw. Deglutition continued halting. The tongue was moist, with fur; he had but little thirst. Temperature $100^{\circ}$. Pulse 90 , feeble. The first sound of the heart was indistinct. Respirations 30, feebly costal. There were no bronchial râles. The bowels had acted very freely, bringing away some old scybala. He had passed urine freely, but was slow in commencing to micturate. His legs were utterly powerless; the muscular power of the arms and hands was enfeebled. He was ordered to continue the medicine, stimulant, and diet, as before ; to have a blister, four inches by four, applied to the spine opposite the cervical and lumbar enlargements of the cord; and the ice-bag to be continued between the two blisters.

Dr. Althaus confirmed my diagnosis of acute myelitis confined to the ganglionic cells in the anterior cornua, commencing in the lumbar region and spreading upwards; the posterior or sensory portions of the cord being intact, as also the strands which contain the trophic and vaso-motor fibres. There was no paralysis of the bladder, nor consequent cystitis ; for, as pointed out by Dr. Althaus, these only go with myelitis affecting the posterior columns of the cord. The absence of twitchings of the limbs, or any convulsive movement, excluded meningitis of the cord. The acute lithiasis and myelitis had probably no connection with each other in the way of cause and effect, but were most likely both due to the same exciting cause-cold; but the proximate cause of the myelitis was probably over-exertion in a debilitated subject, disposed to a neuropathy. Dr. Althaus remarked that this form of disease was very, if not altogether, analogous to infantile paralysis. Ninety per cent. of these cases recover; and if, in the present case, the disease could be prevented from creeping upwards, and so involving the centres of respiration and circulation in the medulla oblongata, all might still be well for the present ; but a certain amount of permanent paralysis possibly loomed in the distance.

September $I \epsilon$ th, 9 A.M. He had not slept, probably owing to the blisters, which had risen well, and set up some irritation. The pupils were less contracted. He had more power in moving the head. Deglutition was much the same. He could use his arms more deci. 
dedly, as also the left foot, which he now moved at the ankle-joint; he could also move the toes of the right foot. He was still unable to turn in bed, or to make any bodily movement whatever. The mental faculties were clear; reflex action was still in abeyance. Pulse 120, feeble; temperature ror. $4^{\circ}$; skin dry. Two grains of ergotine were injected into the left leg. He was ordered to continue focd, medicine, and stimulant, and ice-bag. The blisters were directed to be dressed. -9.15 P.M. He expressed himself as feeling better. He had slept at intervals during the day for two hours, but awoke confused and at a loss for the right word; this, however, passed away in a short time. He complained of a sense of disquietude, partly from a constrained position, which he was unable to change without assistance. $\mathrm{He}$ moved his arms freely, and for the first time volunteered to shake me by the hand. Pulse 98, soft; respirations 26; temperature 99; skin manifestly cooler, and inclined to be moist. He had taken food fairly, and passed urine freely.

September 17th, 9.20 A.M. He had held his ground; had slept well and taken nourishment more readily, swallowing being easier. Pulse 94, of fair power. The first sound of the heart was less indistinct at the base. Respirations 22, sighing in character. Temper 1 ture normal. The bowels had not acted. The urine was very acid, and contained again a pretty copious deposit of uric acid. He had more power in the arms, and could move his head a little without assistance. There was decidedly more power in the left leg-the hamstring muscles contracting, but not powerfully enough to flex the leg upon the thigh. The right leg was powerless; and reflex excitability was wanting. - 7.30 P.M. Dr. Althaus saw him again with me this evening, and was more than satisfied with the progress made. His countenance was cheerful. The pupils were normal; there was no in tolerance of light. Speech was natural. He had taken nourishment well, feeding himself, and asking for solid food. The movement of the jaw was unembarrassed. Deglutition was much easier. Tongue clean; bowels active. Urine clear, and free from sand. Pulse 92, more power. Temperature normal. He could move his head much better, and partially turn himself round in bed. The condition of the lower limbs was much as in the morning. He was ordered to have five grains of ergotine, five minims of tincture of belladonna, and fifteen minims of spirit of chloroform, every six hours, and a dose of castor-oil in the morning. Solid food was allowed. Dr. Althaus remarked that in these cases there was no trusting to nature; active treatment being imperatively necessary. The old practice of leeches, calomel, etc., was generally fatal to a cure, if not to the life of the patient. Two or three cases of withered palsied limbs, the outcome of defective treatment, were brought to him weekly. In cases like the present one, even if the disease were stopped short of the medulla oblongata, a permanent paralysis generally resulted. Dr. Althaus thought all fear of a fatal issue had now passed away; and that we migh fairly count upon the progress already made as an earnest of a speedy and permanent cure. He considered this a typical case, and one that might well serve as an example as regards treatment to be advantageously followed in similar cases.

September 18th, 9.30 A.M. His appearance was cheerful; he swallowed well. He had passed another tranquil night, and held his ground in all other respects. The breathing, pulse, and temperature were normal. Tongue clean; appetite good. The urine was more abundant, of specific gravity I022, superacid, and free from albumen; there was excess of phosphates, and uric acid sand. There being some tormina, an enema was ordered to assist the action of the oil. -6 P.M. He had passed an unquiet day, owing to nausea, vomiting, and the free action of the bowels; and was somewhat exhausted. Pulse 62, feeble, and slightly irregular. He had taken no stimulant or food all the day. Could all this be due to the action of the ergotine? The brandy was ordered to be persevered with every two hours, and liquid nourishment given in addition.

September 19th, 9 A.м. His condition was greatly improved. $\mathrm{He}$ could push down the left leg when flexed; reflex irritability also was restored in it to a great extent, but was absent in the right; irritation of its sole caused movements in the left leg, showing transference of force.

September 2oth. He was going on well, save that he complained of pains in all his limbs, which were relieved by friction and change of position. He could move himself round, with the exception of his legs. Reflex excitability had fully returned to the left leg, but the right gave no response, save through its fellow. The dose of ergotine was reduced to two grains and a half, and that of the tinctuce of belladonna increased to seven minims and a half.

September 22nd. To-day the pains in the limbs, and also in the bowels, returned. The ergotine was stopped, and an anodyne mixture ordered; great relief resulting.
September 23rd. His general health was improved; but the lower limbs were still painful and tender on handling. The left arm did not squeeze as powerfully as the right. The arms and forearms responded well to the stimulus of faradisation; the left leg partially so. The rectus and hamstring muscles acted fairly, and the muscles attached to the fibula very well indeed; the other muscles acted but indifferently. There was no response to the strongest action in the right leg, though it was distinctly felt. The trophic cells were no doubt implicated; and myositis, chiefly of the right limb, was the result. He was ordered to have a gentle continuous current applied for a short time each day, and to take ten grains of iodide of potassium, three grains of carbonate of ammonia, and fifteen minims of spirit of chloroform, thrice daily.

September 24 th. He had been rather restless, which he attributed to the faradisation of yesterday. Temperature normal; pulse 120, rather irritable. The condition of the limbs was much the same. The continuous current (Weiss'), fourteen cells, was applied for two minutes to the lumbar enlargement of the spinal cord, the negative pole being over the umbilicus. The pneumogastric nerve was also galvanised.

September 30 th. All the remedies had been persevered with; but he had made little or no progress. He took abundance of food, but disliked the stimulant, as making him hot and restless; it had, therefore, been reduced almost to zero. There was more power in the arms and shoulders; the left hand was still a little the weaker. The legs were much as before.

October 8th. He was much the same. The power of the lower limbs had not increased, and their nutrition appeared impaired. The right calf measured half an inch less than its fellow. The muscles of the back were weak, and responded but slightly to a strong current. This was also the case with those of the legs, which required fifty cells, and the current to be interrupted, to produce any effect. He was ordered to continue the current. Iodide of sodium was substituted for potassium. Cod-liver oil and an additional glass of wine were ordered to be taken. He was allowed to sit up and go out of doors.

October 23rd. Dr. Hughlings Jackson saw him with me, and gave a gloomy prognosis. The treatment was continued. The muscular power had not increased; but the tenderness and wasting were lessened. The legs, however, were flexed and somewhat rigid, indicating that the lateral columns were implicated. Sensation remained perfect.

November 18 th. But little progress had been made since last report. The legs were almost insensible to fifty cells; but the muscular tenderness was gone. The toes only of the left foot could be moved voluntarily. The muscles of the back were much stronger, and his general health was good. He now passed out of my hands into those of Dr. Roth, who was to try the movement cure.

Through the courtesy of Mr. Bernard Roth, I saw Mr. A. M. in the end of June, I880. His state then was as follows. He could walk about and go up and down stairs with two sticks and a steel support on the right knee and foot. His appetite and bodily functions were good and regular. The muscular condition was as follows. The right serratus magnus was wasted, as compared with the left. The erector spinæ was very much wasted, so that the lumbar transverse processes were prominent; there was no difference between the two sides. Of the glutei muscles, the left was almost normal; the right was considerably wasted, but still with some voluntary power left. The extensors of the knees were practically nil, and almost completely wasted. The patient could just move the patella. There was slight reaction to slowly interrupted galvanisation; nothing to faradisation. The flexor of the right knee was very weak; of the left good. The flexors and extensors of the right foot were nil; of the left, almost normal. There was, however, still considerable reaction to slowly interrupted galvanisation in the right leg; none to faradisation. Sensibility was normal everywhere. Both lower extremities were easily kept at a normal temperature, but soon became cold and blue on exposure. The patient enjoyed swimming, and could do so very well without any help; and, although his legs were rather cold on coming out of the water, they soon recovered their warmth by friction.

Bequests and Donations.-Mr. George Marples, of Brinkcliffe Tower, bequeathed $£ 500$ to the General Infirmary, $£ 500$ to the Public Hospital and Dispensary, and $£ 300$ to the Hospital for Women, all at Sheffield.-Mr. William Miles, of Exeter, has bequeathed $£ 200$ to the Exeter Lying-in Charity, and the West of England Idiot Asylum.Mr. Jas. Nourse has given $£$ IO5 to the Seaside Branch of the Metropolitan Convalescent Institution at Boxhill. - The Right Hon. W. E. Gladstone, M.P., and Mrs. Gladstone, have given $£ 100$ towards the proposed Scarlet Fever Convalescent Home.-St. Peter's Hospital has received $£$ IOo under the will of Mrs. Mary Threlkeld, and $£$ Io ros. frum Mr. T. S. Bazley. - The Goldsmiths' Company have given $£ 25$ to the North Eastern Hospital for Children. 